\title{
Analysis of water vapor LIDAR measurements during the MAP campaign: evidence of sub-structures of stratospheric intrusions
}

\author{
P. D'Aulerio ${ }^{1,2}$, F. Fierli ${ }^{1}$, F. Congeduti ${ }^{1}$, and G. Redaelli ${ }^{2}$ \\ ${ }^{1}$ Institute for Atmospheric Sciences and Climate, CNR, Roma, Italy \\ ${ }^{2}$ Department of Physics, University of L'Aquila, L'Aquila, Italy
}

Received: 17 August 2004 - Published in Atmos. Chem. Phys. Discuss.: 15 December 2004

Revised: 14 March 2005 - Accepted: 12 April 2005 - Published: 1 June 2005

\begin{abstract}
This paper presents two case studies of transport of dry air in the free troposphere measured by a ground based Raman LIDAR in the Northern-Italy, during the Mesoscale Alpine Programme (MAP). Two observations characterized by the presence of anomalously dry layers, below $6 \mathrm{~km}$ height, were analyzed using Lagrangian techniques. These events are related to upper-tropospheric, high Potential Vorticity (PV) streamers crossing the Alpine region. These are interpreted as small-scale features of stratospheric intrusions associated with the PV ridge during its phase of dissipation. One of the measurements also shows the presence of two distinct dehydrated structures associated with the same event. The water vapor concentration also suggests dilution processes of dry stratospheric air in the troposphere. Lagrangian simulations allowed to successfully reproduce the observed water vapor distribution and the air parcel histories confirmed the stratospheric origin of the dry layers.
\end{abstract}

\section{Introduction}

The transfer of stratospheric air in the troposphere is considered among the key mechanisms influencing the short term variability of the water vapor distribution in the upper-troposphere (SPARC, 2000). Evidence indicates that Stratosphere-Troposphere exchanges (STEs) are also the most important natural factor to impact the tropospheric ozone budget; therefore, due to the radiative properties of ozone and water vapor, these mechanisms can have a strong bearing on the radiative balance. Moreover, the intrusions of PV-rich and dry air in the troposphere can influence the cyclogenesis, the intrusion can drive the PV positive anomaly over the whole tropospheric column and the dry air filaments

Correspondence to: P. D'Aulerio

(p.daulerio@isac.cnr.it) can interfere with convective episodes (e.g. Browning and Golding, 1995; Rossa et al., 2000; Vaughan and Worthington, 2000, and references therein).

Stratospheric intrusions at middle latitudes are mainly associated with tropopause folds (Danielsen, 1968) and can be observed at the synoptic scale as streamers of dry air on satellite images (Appenzeller and Davies, 1992) or anomalies of Potential Vorticity (PV) on isentropic maps (Holton et al., 1995). This is due to the dramatic differences in ozone, water vapor and PV between stratospheric and tropospheric air (Appenzeller et al., 1996). A higher resolution of the streamers within the synoptic representation is achieved by comparing the specific humidity to the corresponding PV, as shown by Gray et al. (1994) and Cox et al. (1995).

Stratospheric intrusion events are not always representative of an effective exchange between the stratosphere and troposphere. In fact, irreversible transport depends on the degree of fragmentation in the finer structures of the air transported from the stratosphere down into the troposphere (Vaughan et al., 1994; Appenzeller et al., 1996; Langford and Reid,1998). As a result of the filamentation, laminar distributions along the vertical profiles of the transported chemical species appear with respect to the climatological profiles (Newell et al., 1999), with a rapidly decreasing vertical depth versus time (Methven et al, 2003). Filaments are generated in regions with strong wind shear (i.e. strong PV gradients) and they can persist in the atmosphere several days later than the intrusion in the troposphere (Bithell et al., 2000). The irreversible mixing of stratospheric and tropospheric air during the lifetime of the folding, is influenced by different mechanisms such as radiative processes, turbulence and molecular diffusion (Shapiro, 1980; Appenzeller et al., 1996; Forster and Wirth, 2000).

The impact of such episodes in the quantitative crosstropopause flux and a complete definition of mechanisms responsible for irreversible mixing can be still considered

(C) 2005 Author(s). This work is licensed under a Creative Commons License. 
crucial aspects for an appropriate description of STE in the extratropics, as summarized in the review paper of Stohl et al. (2003).

The observations of deep intrusion episodes, along with their reproduction in numerical models, represent an important requirement for such purposes. In fact, it has been shown that the occurrence of deep intrusions in the lowermost troposphere can impact the efficiency of the exchange, favoring irreversible transport (Eisele et al., 1999).

LIDAR presented itself as an appropriate tool to resolve the spatial scale of the structures associated with the folding and to provide information about the evolution of such small scale features. This is due to the high spatial and temporal resolution of data and the capability of a continuous sounding (over several hours) of ozone and water vapor profiles (Ancellet et al., 1991; Langford and Reid, 1998; Eisele et al., 1999; Ravetta and Ancelett, 2000; Bertin et al., 2001).

This paper presents the analysis of tropospheric water vapour measurements from a ground-based LIDAR during the MAP-SOP (Mesoscale Alpine Programme - Special Observing Period) campaign. The use of water vapour as a tracer of stratospheric intrusions allows for the clear identification of small-scale $(<1 \mathrm{~km}$ thick) dry structures as filaments originating from the stratosphere. These filaments penetrate into the lower troposphere (down to $3000 \mathrm{~m}$ ) and persist for at least $48 \mathrm{~h}$ after their intrusion. In the first part of the paper the measurement technique, the error budget assessment and the modeling tools are presented. The second part of the paper is devoted to the analysis of two case studies, focusing on a quantitative comparison between simulations and the measured water vapor profiles and on the identification of the origin of the observed dry air by using Lagrangian techniques.

\section{Measurements}

A RMR (Rayleigh/Mie/Raman) LIDAR was deployed during the MAP-SOP in Pallanza di Verbania $\left(45.9^{\circ} \mathrm{N}-\right.$ $8.5^{\circ} \mathrm{E}, 200 \mathrm{~m}$ a.s.1.), inside the "Lago Maggiore Target Area"(Northern Italy). The main purpose of the MAP program was the study of extreme events influenced by orography and the improvement of complex topography effect within numerical models (Bougeault et al., 2002). In this framework, the study of the role of upper-tropospheric PV anomalies on the alpine meteorology was a main task, requiring also the investigation of the fine-scale structures and their influence on atmospheric processes in the alpine region. In fact, interactions of PV anomalies with orography has been indicated as an element affecting meteorological events such as cyclogenesis and precipitation on the Alpine lee side (Massacand et al., 1998; Liniger and Davies, 2003).

The LIDAR, developed at ISAC-CNR (Institute of Atmospheric Sciences and Climate - National Research Council), is schematically composed of a transmitter sending two- laser beams vertically into the atmosphere, at wavelength of $532 \mathrm{~nm}$ and $355 \mathrm{~nm}$ (second and third harmonics of an Nd:YAG pulsed laser) and of a multichannel receiver. The experimental configuration was designed for retrieving water vapor, temperature and aerosols with maximum accuracy in the widest atmospheric range. The basic resolution of acquisitions is $1 \mathrm{~min}$ in time and $75 \mathrm{~m}$ in altitude using photocounting (Congeduti et al., 2002). In the data processing, a time integration is performed and a vertical 7-points rectangular smoothing is applied above $6000 \mathrm{~m}$, with the effect of reducing the vertical resolution from $75 \mathrm{~m}$ to $525 \mathrm{~m}$.

The water vapor profiles, in mixing ratio units, are determined by inverting the ratio of the signal corresponding to the $355 \mathrm{~nm}$-Raman shifted radiation that is backscattered by $\mathrm{H}_{2} \mathrm{O}$ and $\mathrm{N}_{2}$ atmospheric molecules.

This ratio is proportional to water vapor concentration, since the molecular nitrogen can be assumed to have constant mixing ratio within the altitude range of measurements. In order to retrieve the water vapor in mixing ratio units, it is necessary to estimate a constant, depending on the instrumental characteristics, by comparison with an independently measured water vapor profile. The detailed inversion procedure is described in literature (e.g. Whiteman et al., 1992). For each single measurement session, the LIDAR profiles have been compared with high-resolution radiosoundings launched at Milano Linate Airport, $75 \mathrm{~km}$ southeast of the LIDAR site, in the proximity of a large urban area and inside the Po valley. The comparison shows generally a good agreement between the instruments in the free troposphere, particularly in absence of strong horizontal motion. As expected, significant differences are found in the PBL where the water vapor distribution is strongly related to local conditions. For this reason, the calibration procedure is always performed at an altitude above $2000 \mathrm{~m}$. The radiosonde-LIDAR comparison also allowed for an upper estimation of the systematic error introduced by the calibration method of $10 \%$. On average, the statistical uncertainty is less then $10 \%$ up to the middle troposphere, increasing up to more than $40 \%$ in the upper troposphere ( $>9 \mathrm{~km}-10 \mathrm{~km}$ ), for an integration time of $30 \mathrm{~min}$. The signal to noise ratio also depends on the absolute moisture concentration, for example in dry conditions higher values for the statistical error are expected. Generally, the water vapor data acquired during the campaign by the Raman LIDAR are available from few hundred meters above the ground up to a maximum altitude of $10-10.5 \mathrm{~km}$. During the campaign, 26 nighttime LIDAR measurements were carried out for a total of $160 \mathrm{~h}$ of observations. Two observations during tropopause folding episodes detected above the Alpine region were identified and analyzed in the following part of the paper. 


\section{Lagrangian simulations}

To interpret LIDAR observations, Lagrangian simulations from the trajectory model FLEXTRA (Stohl, 1998) have been performed. The model uses the analysis of the European Centre for Medium-Range Weather Forecasts (ECMWF) operational global assimilation schemes at a $3 \mathrm{~h}$ temporal resolution, $0.5^{\circ} \times 0.5^{\circ}$ horizontal resolution and 60 vertical levels (T312 truncation).

"Coherent Ensemble of Trajectories" (CETs) have been simulated starting from regular grid point. This method is shown to be appropriate in the study of extratropical cyclones and cross-tropopause exchanges (Wernli and Davies, 1997). In the present study, 3-D and isentropic CET have been calculated in a domain around the lidar position in order to identify the origin of the measured air parcel. The time-length of simulations ranges between $48-96 \mathrm{~h}$, depending on the numerical dispersion of the trajectory cluster.

The 3-D grid is defined in a spatial range between $42^{\circ} \mathrm{N}$ and $50^{\circ} \mathrm{N}$ in latitude and $4.5^{\circ} \mathrm{E}$ and $12.5^{\circ} \mathrm{E}$ in longitude, with an horizontal resolution equal to the ECMWF data (i.e. $0.5^{\circ}$ ), for an altitude range between 3 and $8 \mathrm{~km}$, with $250 \mathrm{~m}$ of vertical resolution. Since the 3-D trajectories provided more accurate reproduction of the observed characteristics with respect to the isentropic, only the results of 3-D simulations are shown in this context.

The back-trajectories are also used to reproduce high resolution water vapor and PV fields by a Lagrangian Tracer Reconstruction (LTR) method, based on the Reverse Domain Filling (RDF) technique.

The RDF technique, originally proposed by Sutton et al. (1994), has been extensively employed in studies concerning the dynamic of the polar vortex and the interpretation of laminae measured in stratospheric ozone profiles (Orsolini et al., 1998). This approach has been also used in the simulation of tropospheric moisture (Pierrehumbert, 1998) and ozone and water vapor distributions in the upper troposphere (Methven et al., 2003; Liniger and Davies, 2003).

A simplified variant of this technique has been applied for LTR imposing, to each grid point, the specific humidity concentration and PV, experienced by the air parcels along the back-trajectory at a defined time $\tau$, under the hypothesis that these parameters are conserved during this time interval.

This method amplifies the gradients in the physical parameters, not resolved by conventional meteorological analysis. In fact, if neighboring parcels have a different origin, their back-trajectories spread out with increasing of simulation time.

The time length $\tau$, is limited by the water vapor and PV conservation. In fact, while in the stratosphere water vapor and PV can be assumed to be conserved for 10-15 days on an isentropic surface (Knudsen and Carver, 1994), the tropospheric water vapor is characterized by a lower conservation time scale, affected by condensation phenomena and diabatic motion. Moreover, trajectory dispersion can lead, in some cases, to an unrealistic field reconstruction. For the results presented in this paper, values of $\tau$ ranging between $12-24 \mathrm{~h}$ have been chosen in order to optimize the agreement with the LIDAR measurements.

The water vapor concentrations obtained by the simple application of LRT, compared with the measured values, indicates that condensation along the trajectories can lead to an overestimate of the water vapor content by the simulation. In order to avoid this effect, the advection is performed backward in time, until reaching saturation conditions when the "memory" of previous water vapor content along the trajectory has been lost (Pierrehumbert, 1998). The reconstructed mixing ratio was then assumed equal to the minimum value of saturation mixing ratio within the chosen interval, under the realistic hypothesis to be outside of a region characterized by relevant sources of moisture. By this procedure the humidity excess is rather well eliminated when compared with the observations.

\section{November 1999 case study during the MAP IOP 15}

A PV anomaly, developed in the Western Atlantic and experiencing a southeastward motion, crossed the Alpine region between 5 and 8 November 1999. The MAP IOP 15 (Intensive Observing Period) was dedicated to the study of this event (Bougeault et al., 2002; Hoinka et al. 2003; Liniger and Davies, 2003). The early and central phase of the streamer evolution was characterized by strong rain conditions associated with the orographic cyclone that developed on the alpine lee-side (Buzzi et al., 2003). This allowed for LIDAR observations only after 7 November at 8 p.m. until 2 a.m. of the following day, when the streamer is found in the stage of dissipation, as seen in the simultaneous synoptic PV maps (not reported).

Hoinka et al. (2003) reports the stratospheric intrusion as observed by airborne the DIAL LIDAR on 6 November at 15:00 UT during the flight along the $45^{\circ} \mathrm{N}$ parallel from $1.5^{\circ} \mathrm{W}$ to $12^{\circ} \mathrm{E}$. Water vapor sampled in a vertical range between $5-10 \mathrm{~km}$ indicates that stratospheric air penetrates down to $6 \mathrm{~km}$ and the typical $\mathrm{V}$-shape of a tropopause fold (Browell et al., 1987) is reproduced in the vertical crosssection.

Liniger and Davies (2003) performed simulations of the water vapor field, also based on a Lagrangian approach, for 6 November, and compared it to the DIAL data. The authors showed the occurrence of a secondary fold on the western edge of the streamer and a rich filamentation associated with the principal intrusion, while the simultaneous airborne LIDAR data exhibit a hint of the secondary fold, but no evidence for these filamentary structures (Hoinka et al., 2003).

The time evolution of the water vapor specific humidity, measured $30 \mathrm{~h}$ later by the ISAC RMR LIDAR, is reported in Fig. 1 and plotted as a succession of 15-min averaged profiles. 

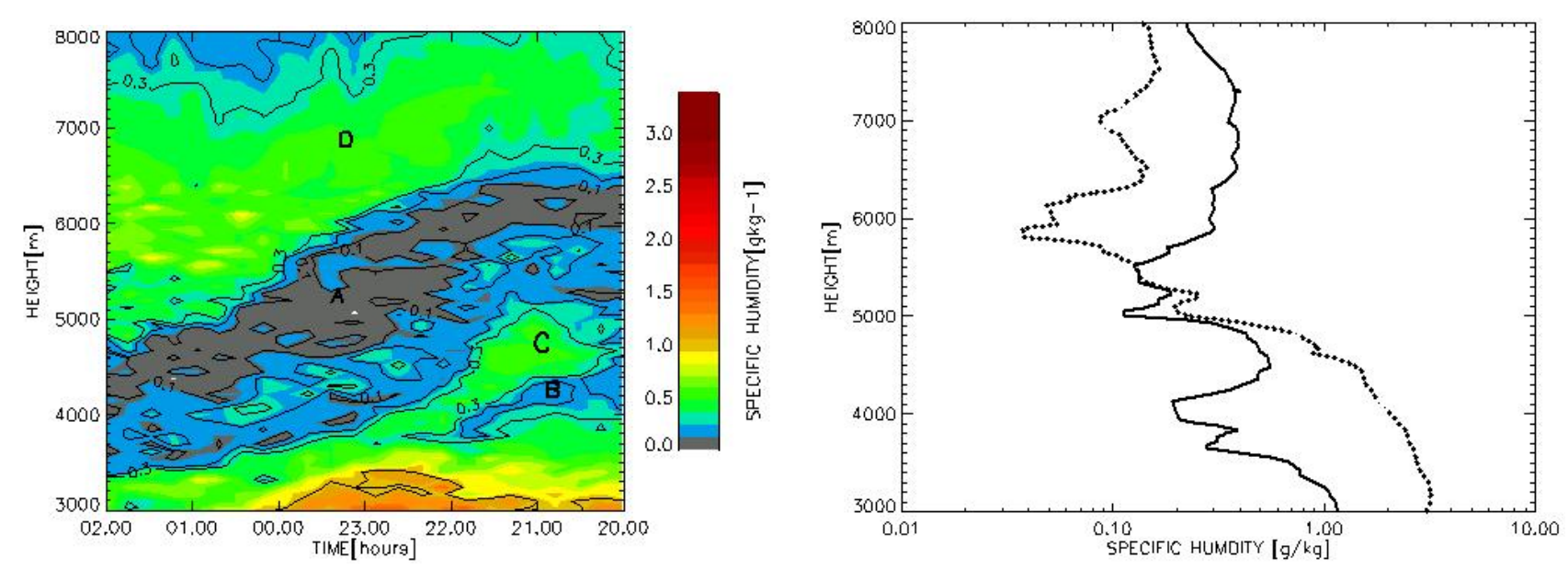

Fig. 1. Time evolution of water vapor vertical profiles measured by LIDAR from 7 November 1999 at 20:00 UT until 8 November at 02:00 UT. The time in the x-axis is from left to right. The color code corresponds to the specific humidity. On the right specific humidity profiles measured in Milano Linate at 18:00 (dotted line) and 00:00 UT (bold line) are shown.

The water vapor exhibits a high variability during the measurement period and several layers are clearly noticeable. In particular, two distinct dry laminae are measured between 8 p.m. on 7 November and 2 a.m. the following day. The larger layer $(\sim 500 \mathrm{~m}$ thick, indicated by A in Fig. 1) in the middle-troposphere descends during the measurement from $6 \mathrm{~km}$ to $4 \mathrm{~km}$ in altitude. The corresponding specific humidity is less than $0.05 \mathrm{~g} / \mathrm{kg}$, a value definitely close to the limit of sensitivity of the ground based Raman system. This concentration indicates clear dryness, up to one order of magnitude, compared to the average concentration measured at these heights. Conversely, the upper layer between $6000-8500 \mathrm{~m}(\mathrm{D})$, is variable throughout the measurement and exhibits typical tropospheric values of specific humidity $(\sim 0.5 \mathrm{~g} / \mathrm{kg})$. The second thin and dry tongue, with a water vapor concentration close to $0.1 \mathrm{~g} / \mathrm{kg}$, moves downward between 4 and $3.5 \mathrm{~km}$ (B), narrowing with time and disappearing after 11 p.m. Finally, a moist structure, embedded between the A and B dry layers, is measured at $4 \mathrm{~km}(\mathrm{C})$ during the first $2 \mathrm{~h}$ of the observation.

Figure 1 also reports the humidity profiles from the highresolution radiosoundings in Milano-LINATE, at 6 p.m. 7 November and $0 \mathrm{a} . \mathrm{m}$. the following day. A dry layer with a specific humidity of $\sim 0.04 \mathrm{~g} / \mathrm{kg}$ (and relative humidity reaching $\sim 2 \%)$ is observed at $\sim 490 \mathrm{hPa}(5800 \mathrm{~m})$ at $6 \mathrm{p} . \mathrm{m}$. (about $3 \mathrm{~h}$ before the beginning of lidar session in Pallanza di Verbania). The following soundings show that the layer moves downward with a behavior similar to that observed by LIDAR. The 0 a.m. profile shows, in agreement with LIDAR measurements, the presence of the moist substructures at $5 \mathrm{~km}$, embedded between the two dry layers. The presence of the upper layer is consistent with the generation of a secondary fold at the west of the primary and its tran- sition above the radiosounding station after the 18:00 UT. Nevertheless the water vapor structures measured by LIDAR and radiosounding appear to be temporally shifted, consistent with the reciprocal position of the two observation sites and eastward displacement of the PV streamer.

LIDAR data measured the following night (between 8 and 9 November, not reported) show a moderate dryness of the troposphere above $6 \mathrm{~km}$, while the evidence of laminar structures has vanished. The corresponding back-trajectories show a common geographical origin of the air particles ending at different altitudes between 5 and $8 \mathrm{~km}$ and the corresponding longitudinal cross section (obtained by LTR as Fig. 2) appears consistent with the measured water vapor.

CETs are calculated backward from the LIDAR site, between 7 p.m. 7 November and 2 a.m. the following day, in order to cover the whole time and vertical range of the observations.

Results show that different ensembles of trajectories, converging in the Alps area, can be identified based on their geographical origins, water vapor and PV evolution. A good match is found in altitude between the heights of trajectories and the observed atmospheric layers, characterized by different water vapor concentration. Trajectory clusters ending at the average altitude and time of the observed layers are selected and identified with the notation given if Fig. 1. Holding the longitude at $8.5^{\circ} \mathrm{E}$ and the latitude ranging between $45^{\circ}-47^{\circ} \mathrm{N}$, the main features of each cluster are reported below:

A: Trajectories ending at an average altitude of $6400 \mathrm{~m}$ at 8 p.m., where the main dry layer is measured by LIDAR. These descend from an height ranging between $10 \mathrm{~km}$ and $11 \mathrm{~km}$ above the Northern Canada; $72 \mathrm{~h}$ before the observations, the average $\mathrm{PV}$ is $3.6 \mathrm{PVU}$ 

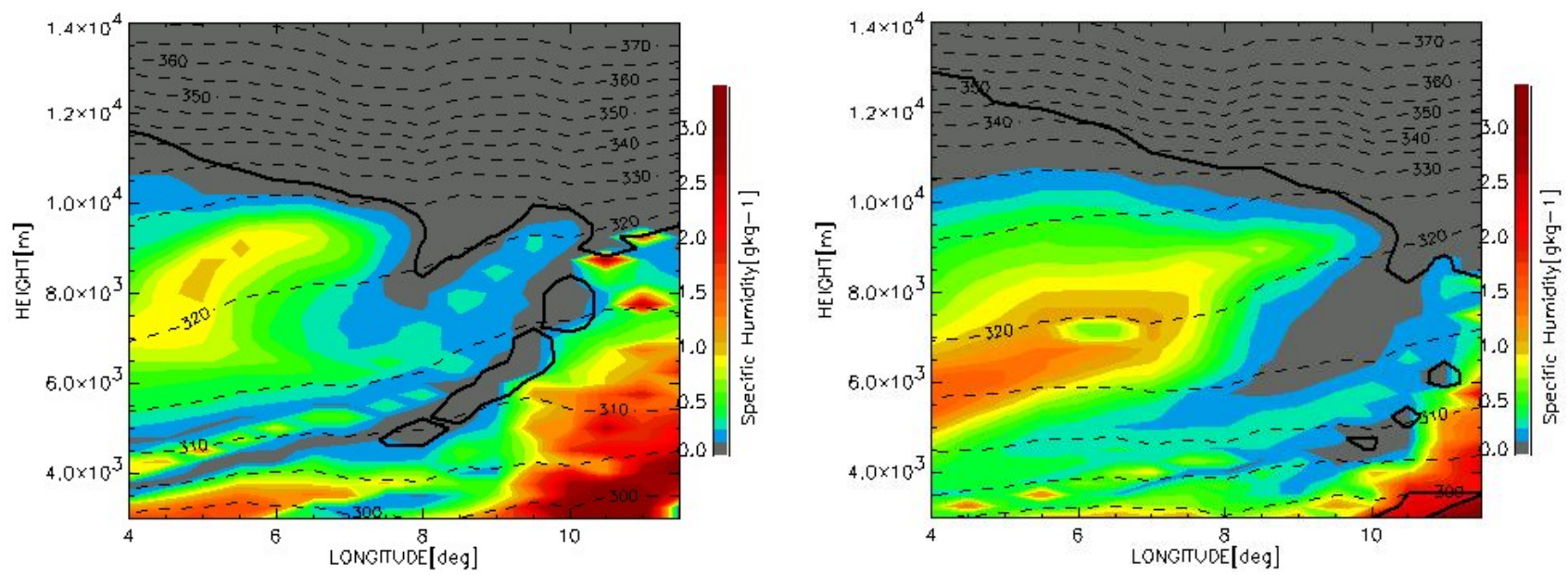

Fig. 2. W-E oriented cross section along $46^{\circ} \mathrm{N}$ showing the residual tropopause fold on 7 November at 15:00 UT (left) and at 20:00 UT (right). Color code corresponds to specific humidity, the black continuous line corresponds to 1.5 PVU (as obtained by LTR) and the dotted lines indicate potential temperature levels (every $5 \mathrm{~K}$ ). The LIDAR site is based at $8.5^{\circ} \mathrm{E}$ at the center of $\mathrm{x}$-axis.

(1 PVU $=10^{-6} \mathrm{~m}^{2} \mathrm{~s}^{-1} \mathrm{~K} \mathrm{~kg}^{-1}$ ) and the specific humidity is $0.02 \mathrm{~g} / \mathrm{kg}$.

B: Trajectories ending in a range centered at $3.6 \mathrm{~km}$ in altitude at 20:00 UT, also characterized by high PV values (2.5 PV units) and low specific humidity $(0.03 \mathrm{~g} / \mathrm{kg}$ ) at the beginning of the simulation.

C: Trajectories ending between $4-5 \mathrm{~km}$, are composed of two different groups converging in the observations area. One ascends from the lowermost troposphere (2$3 \mathrm{~km}$ a.s.1.), while the second group travels constantly in a range of heights between $5 \mathrm{~km}$ and $6 \mathrm{~km}$.

D: Finally parcels corresponding to the moister layer above $7 \mathrm{~km}$ ascend from $\sim 6 \mathrm{~km}$ and their water vapor content decrease along the path due to condensation effects.

Based on this lagrangian analysis, the two dry layers detected by LIDAR appear to be generated by downward motion from UT-LS (Upper Troposphere-Lower Stratosphere) region. This is highlighted by the signature in water vapor and PV, according to the PV values (1.5-2.0 PVU) indicated in literature (e.g. Appenzeller et al., 1996) as representative of the dynamical tropopause.

Figure 2 reports the water vapor vertical distribution obtained by LTR as a function of the longitude, at the latitude $46^{\circ} \mathrm{N}$, on 7 November at 15:00 UT and at 20:00 UT. The whole structure moves eastward with time. Two folds are clearly reproduced on PV and water vapor in agreement with the findings of Liniger and Davies (2003). Moreover, dry thin laminae, not evident in the reconstructed PV field, originate from the main streamer. The LTR is consistent with the LIDAR measurement (carried out at $8.5^{\circ} \mathrm{E}$ ) and in qualitative agreement with the observed water vapor layering: the LTR water vapor at the LIDAR coordinate clearly exhibits two different dry layers originating from the upper tropospheric folding, in the first simulation. Moreover, the LTR indicates a progressive descent of the main dry layer consistent in altitude and apparent lowering speed with the observed one. In the 20:00 UT simulation, the lower layer is still identified but, especially in PV, this appears much less marked with respect to the previous stage.

In order to compare the simulations and the observations on a quantitative basis, Fig. 3 reports the water vapor time evolution simulated by the LTR, simultaneously to the LIDAR observations. The LTR water vapor shows the presence of the observed structures, in agreement with altitude, time, and water vapor concentration. The back-trajectory analysis confirms that LIDAR sampled the dry remnants of the PV streamer and that the moist "sandwiched" layer is composed of air originating from the lowermost maritime troposphere.

In the first part of simulation, below $5 \mathrm{~km}$, a noisy distribution is obtained due the dispersion of trajectories ending at the corresponding altitude range.

Figure 3 also reports the direct comparison of the simultaneous vertical profile of water vapor LIDAR, LTR and ECMWF ) between 00:00 and 01:00 UT. The LTR profile is in good quantitative agreement with the measured one in the 4000-6000 m dry layer, while the ECMWF profile does not show any evidence of dry air in the $3000-5000 \mathrm{~m}$ layer. The simulated water vapor is higher than the observed concentration in the driest part of the layer at $4800 \mathrm{~m}$. In fact, the limited vertical resolution of the LTR $(250 \mathrm{~m})$ could inhibit the detailed reconstruction of the thinner observed layers. 

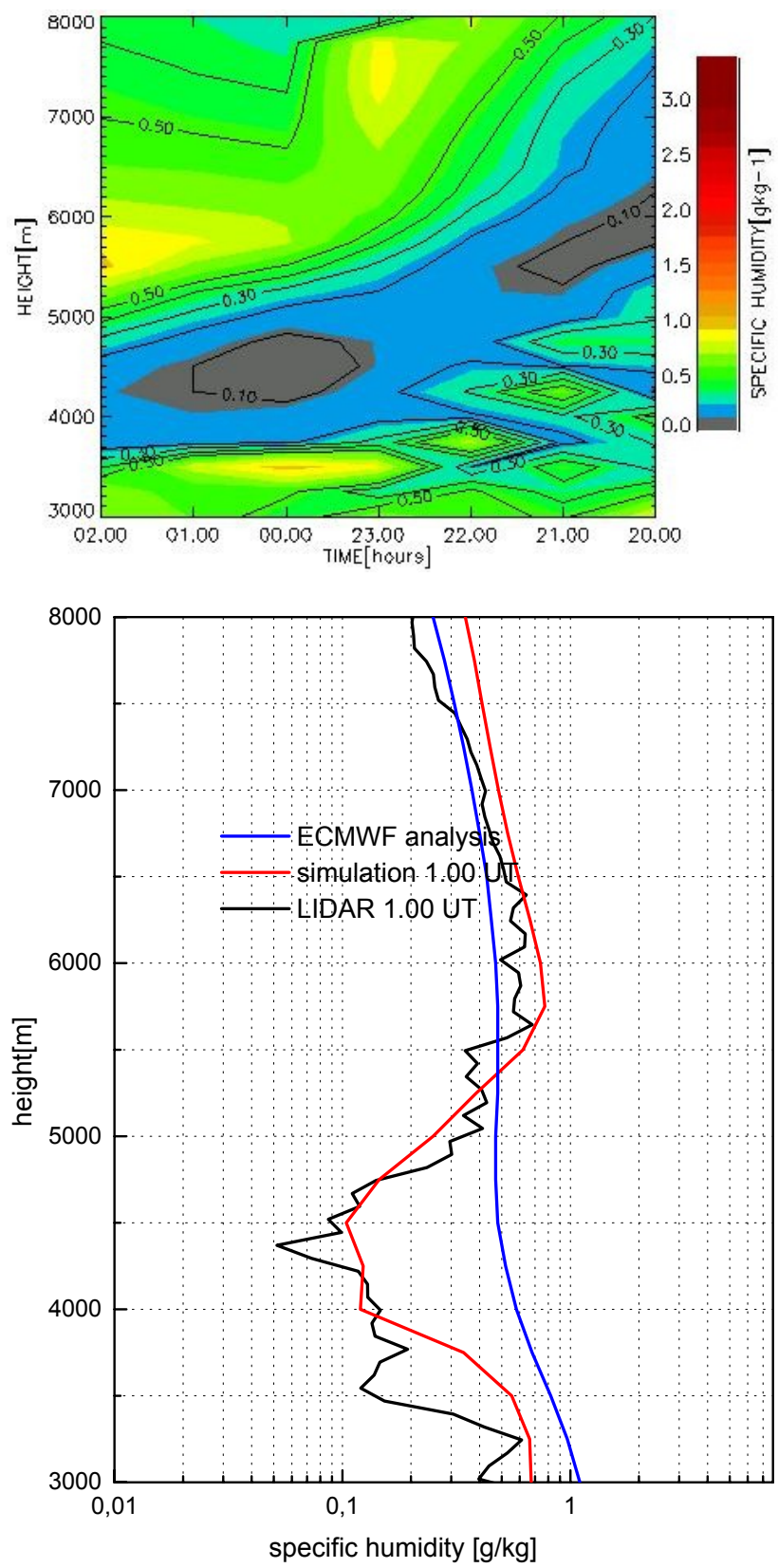

Fig. 3. Water vapor time evolution as simulated by the LTR in the interval 20:00-02:00 UT for 7 November (left). The time in the xaxis is from left to right. On the right comparison of water vapor vertical profiles from 1hour integrated LIDAR (black line), LTR simulation (red line) and ECMWF analysis (blue line) is shown.

\section{September 1999 case study}

A PV anomaly above Europe, extending southward from the Scandinavian region, characterized the synoptic condition for about $24 \mathrm{~h}$ before LIDAR measurements were carried out in the night between 28 and 29 September 1999. The PV streamer centered on the Alpine region at 12 a.m. 28 September and extending southward to $44^{\circ} \mathrm{N}$, moved east-
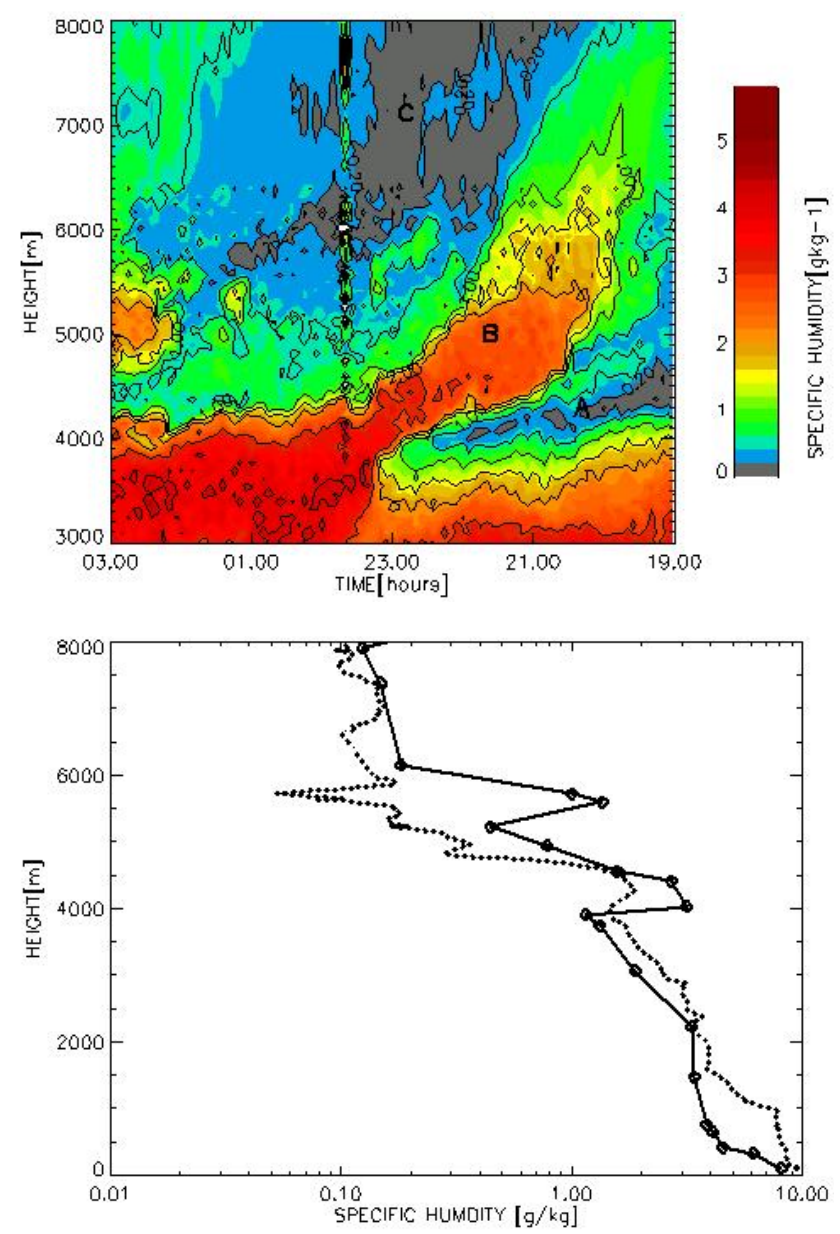

Fig. 4. Time evolution of water vapor vertical profiles, $5 \mathrm{~min}$ integrated, measured by LIDAR from 28 October 1999 at 19:00 UT until 29 September at 03:00 UT. The time in the $\mathrm{x}$-axis is from left to right. The color code corresponds to the specific humidity. On the right specific humidity profiles measured in Milano Linate at 18:00 (dotted line) and 00:00 UT (bold line) are shown.

ward with an horizontal velocity of about $30 \mathrm{~km} / \mathrm{h}$. At 6 p.m. the same day, the core of PV anomaly has completely passed over Northern Italy and was located above Eastern Europe (as seen in the isentropic PV map, not reported).

The LIDAR measurements are reported in Fig. 4. Consistent with the synoptic condition, at the beginning of the measurement (between 6.30 p.m. and 11.30 p.m.) a dry layer (A) with values close to $0.09-0.1 \mathrm{~g} / \mathrm{kg}$ is observed, moving downward from $5000 \mathrm{~m}$ to $4000 \mathrm{~m}$. Its thickness decreases during the first four hours and it disappears afterwards. The Milano-Linate radiosounding, launched at 6 p.m., also exhibits the evidence of a dry layer at $500 \mathrm{hPa}$, with a specific humidity of $0.07-0.09 \mathrm{~g} / \mathrm{kg}$ (a relative humidity of $2-$ $3 \%$ ). The midnight radiosounding, only available at mandatory levels for this day, shows an increase in the minimum relative humidity of $10 \%$ and values for the specific humidity up to $0.4 \mathrm{~g} / \mathrm{kg}$. 
In this case the disappearance of the dry layer can be explained by the synoptic evolution of the streamer, also leading to a transition from dry to moist conditions in the lowermost part of the troposphere.

The water vapor content inside this dry layer is definitely lower than the surrounding air; nevertheless, the observed concentration is greater than what would be expected in the lower stratosphere region.

An abrupt change in the condition is observed after 11 p.m. with a dramatic increase in water vapor concentration in the $3000-4000 \mathrm{~m}$ layer, from $\sim 0.1 \mathrm{~g} / \mathrm{kg}$ to $4-5 \mathrm{~g} / \mathrm{kg}$ (B). Finally, a dry layer $(\mathrm{C})$, descending from 8000 to $6000 \mathrm{~m}$, is characterized by water vapor concentrations typical of uppertropospheric conditions $(0.2-0.3 \mathrm{~g} / \mathrm{kg})$.

Trajectory simulations, carried out in a similar fashion as 7 November case, are used to identify the origin of the different layers. Three different CETs are identified.

The main features are reported below:

A: Trajectories ending between $4250 \mathrm{~m}$ and $4750 \mathrm{~m}$, at 8 p.m. experience a downward transport from an altitude of 8000-10000 m originated between Iceland and Britain Islands. The mean PV values decrease along the trajectory from 3.5 PVU (PV Units) to 1 PVU. Conversely, the water vapor specific humidity increases from $0.04 \mathrm{~g} / \mathrm{kg}$ to $0.6 \mathrm{~g} / \mathrm{kg}$.

B: Trajectories ending in the same altitude as group A, but at 00:00 UT on 29 September, exhibit the opposite characteristics. These originated in the Atlantic region, uplift from lower troposphere $(\sim 2000 \mathrm{~m})$ up to the middle troposphere (between 3000 and $7000 \mathrm{~m}$ height). The ending altitude of this cluster matches the position of the moist layer observed in the LIDAR data and progressively decreases with time in the following simulations.

C: Finally, the trajectories corresponding to the third dry layer, ending at 00:00 UT in the altitude range of $6.7 \mathrm{~km}-7.2 \mathrm{~km}$, also originated from the upper troposphere but at a lower latitude. They appear to conserve upper tropospheric features (water vapor concentration and PV) and do not show evidences of a stratospheric origin.

The properties shown by the different groups of trajectories appear well related with the distribution of water vapor measured by LIDAR at the corresponding heights and times.

In this case the PV appears more conserved along the trajectory, with respect to the case of 7 November; this is explained with the shorter life-time of the observed streamer.

Figure 5 reports the water vapor vertical distribution from LTR with the same characteristics as in Fig. 2. A dry and high PV streamer extends between $6^{\circ} \mathrm{E}$ and $12^{\circ} \mathrm{E}$, descending at a height of $3500 \mathrm{~m}$. The event is followed by moist air transport, with an indication of ascent in the moister layer at

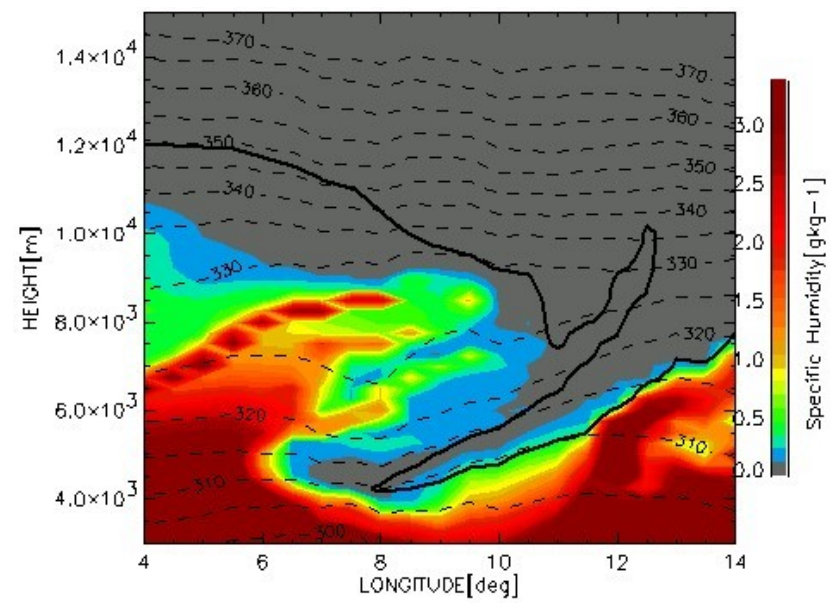

Fig. 5. The same as Fig. 2 but for 28 September at 18:00 UT.

a height of $8000 \mathrm{~m}$ between $5^{\circ} \mathrm{E}$ and $8^{\circ} \mathrm{E}$. The LTR support the hypothesis that deficit of water vapor in the first part of LIDAR observations is related to the intrusion event. In fact the dry layer (A) appears to be associated with the streamer at $4500 \mathrm{~m}$ and the substantial increase in water vapor is related to differential advection of moist air.

Figure 6 reports the water vapor time evolution simulated by the LTR as in Fig. 3.

The values of Potential Vorticity given by the simulation at the time of measurements, not shown, describe the exact correspondence between low water vapor concentration and maximum PV values (1.5-2.0 PVU ) for the lowermost layer, that appears as the lower tip of the principal fold passing over the LIDAR site.

Vice versa the second dry layer on measurements and simulations in the range of $6-8 \mathrm{~km}$ shows values that are not representative of the stratosphere, suggesting that it is of a completely tropospheric origin.

\section{Discussion and conclusions}

The analysis of two LIDAR observations during the MAP 1999 campaign indicated the presence of dry layers penetrating deeply in the lowermost free troposphere. These small scale structures $(300 \mathrm{~m}-1 \mathrm{~km})$ observed by Raman LIDAR are related to the presence of upper tropospheric PV streamers and identified as filaments of air intruding from the lowermost stratosphere. The measurements were taken during the final stage of these events and the different layers detected by LIDAR cannot be observed in the conventional ECMWF meteorological analysis due to their coarse resolution. A Lagrangian technique based on the principle of Reverse Domain Filling is used to simulate the measured field resolving most of the observed layering.

The simulated field also allowed a direct comparison of the water vapor content and potential vorticity values inside 

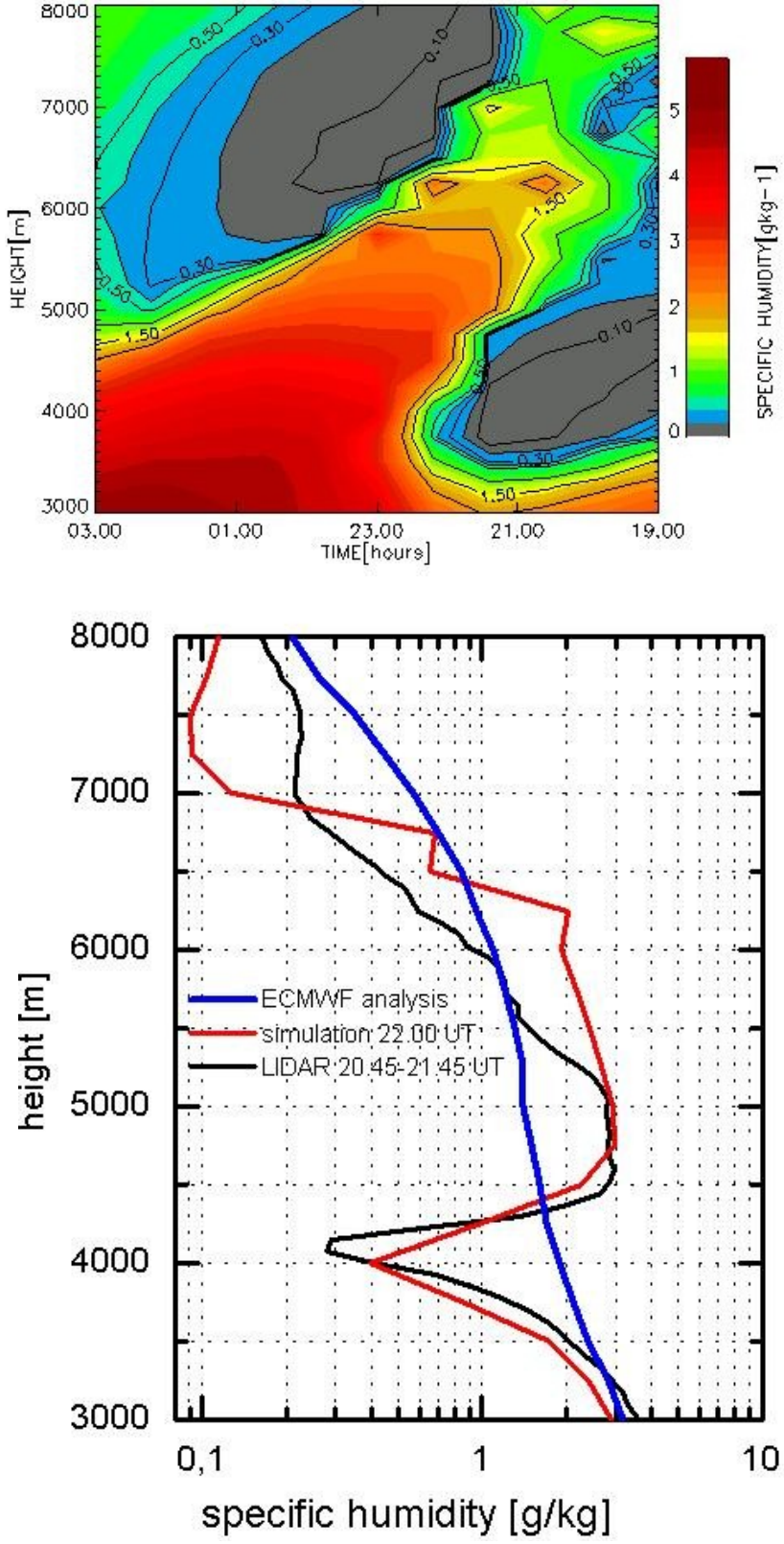

Fig. 6. Water vapor time evolution as simulated by the LTR in the interval 19:00 UT-03:00 UT for 28 September (left). On the right comparison of water vapor vertical profiles from 1hour integrated LIDAR (black line), LTR simulation (red line) and ECMWF analysis (blue line) is shown.

the dry layers. The occurrence of a simultaneous low water vapor concentration and maximum Potential Vorticity inside the same layers, along with the time-history of the corresponding back-trajectories confirms an origin from the lowermost stratosphere for these dry structures. For the 7 November case, the occurrence of two distinct descending dry tongues is well identified and related to a double folding, also confirmed by the reconstructed Lagrangian PV field.
Following their temporal evolution, the dry filaments have been observed to narrow and penetrate deeply in the troposphere ( the lowermost detected down to $\sim 3.5 \mathrm{~km}$ ). Moreover the dry layers are interleaved by moister air. This feature appears consistent with that shown in the analysis of the same event at a previous stage (Liniger and Davies, 2003) simulated by analogous technique but not supported by the observational evidence.

The values of specific humidity measured inside the dry layers have been compared with those provided by ECMWF at the origin of the air parcels trajectory. The two layers detected at the lower altitude $(3-5 \mathrm{~km})$, in both the two cases studied, appear characterized by values higher than those expected in the lower stratosphere, suggesting the occurrence of a progressive dilution of the air penetrating down through the troposphere. Furthermore, simulations indicates that such layers are an extreme filamentation of the fold, where strong mixing is expected (Browell et al., 1987). In addition, the behavior of chemical and dynamical parameters along the trajectory shows a loss of PV and an increase in water vapor along the 48-96 h paths.

This appears in agreement with that found in previous observational studies of ozone filaments persisting in the free troposphere (Vaughan et al., 2000; Bertin et al., 2001), that also indicates different behavior in the dissipation of chemical and dynamical tracers.

Lower values of specific humidity are, instead, measured inside the upper dry layer on the 7 November case $(\sim 0.05 \mathrm{~g} / \mathrm{kg})$. The comparison of these values with those at the origin of the trajectory, by ECMWF analysis, $(\sim 0.03 \mathrm{~g} / \mathrm{kg}$ ), seems to indicate a less evident effect of dilution. Moreover, the LTR fields suggest a different behavior in the evolution of UT-LS water vapor and Potential Vorticity along the trajectories: low concentration of water vapor appears to be better conserved than positive PV anomalies.

The orographic effect due to the interaction with the Alpine ridge could play a role in the streamer evolution. In fact, the Canadian MC2 limited area model (Benoit et al., 1997) simulations (not reported and available at http: //www.map.ethz.ch) indicate that the PV layers originating from the tropopause folding are dissipated above the relief before the measurements.

Acknowledgements. P. D'Aulerio was supported by a $\mathrm{PhD}$ grant from the University of L'Aquila. The author wishes to acknowledge ECMWF for providing the meteorological analyses and the European Science Foundation for supporting the ACPD special issue. The authors wish to thank A. Buzzi for fruitful discussions.

Edited by: D. McKenna 


\section{References}

Ancellet, G., Pelon, J., Beekmann, M., Papayannis, A., and Megie, G.: Ground-Based lidar studies of ozone exchanges between the stratosphere and the troposphere, J. Geophys. Res., 96, 22 40122 421, 1991.

Appenzeller, C. and Davies, H. C.: Structure of stratospheric intrusion into the troposphere, Nature, 358, 570-572, 1992.

Appenzeller, C., Davies, H. C., and Norton, W. A.: Fragmentation of stratospheric intrusions, J. Geophys. Res., 101, 1435-1456, 1996.

Benoit, R., Desgagné, M., Pellerin, P., Pellerin, S., Desjardins, S., and Chartier, Y.: The Canadian MC2: a semi-Lagrangian, semiimplicit wide-band atmospheric model suited for fine-scale process studies and simulation, Mon. Weather. Rev., 125, 23822415, 1997.

Bertin, F., Campistron, B., Caccia, J. L., and Wilson, R.: Mixing processes in a tropopause folding observed by a network of ST radar and lidar, Ann. Geophys., 19, 953-963, 2001,

SRef-ID: 1432-0576/ag/2001-19-953.

Bithell, M., Vaughan, G., and Gray, L. J.: Persistence of stratospheric ozone layers in the troposphere, Atmos. Environ., 34, 2563-2570, 2000.

Bougeault, P., Binder, P., Buzzi, A., Dirks, R., Houze, R., Kuettner, J., Smith, R. B., Steinacker, R., and Volkert, H.: The MAP Special Observing Period, Bull. Amer. Meteor. Soc., 82, 433-462, 2002.

Browell, E. V., Danielsen, E. F., Ismail, S., Gregory, G. L., and Bleck, S. M.: Tropopause fold structure determinated from airborn lidar and in situ measurements, J. Geophys. Res., 92, 2112 2120, 1987.

Browning, K. A. and Golding, B. W.: Mesoscale aspects of a dry intrusion within a vigorous cyclone, Q. J. R. Meteorol. Soc., 121, 463-493, 1995.

Buzzi, A., D'Isidoro, M., and Davolio, S.: A case study of an orographic cyclone south of the Alps during the MAP-SOP, Q. J. R. Meteorol. Soc., 129, 1795-1818, 2003.

Congeduti, F., Medaglia, C. M., D’Aulerio, P., Fierli, F., Casadio, S., Baldetti, P., and Belardinelli, F.: A powerful trasportable Rayleigh-Mie-Raman LIDAR System, International Laser Radar Conference, edited by: Bissonette L., Roy, G., Vallée, G., Defence R\&D, Quebec, Canada, 2002.

Cox, B. D., Bithell, M., and Gray, L. J.: A general circulation model study of a tropopause folding event at middle latitudes, Q. J. R. Meteorol. Soc., 121, 883-910, 1995.

Danielsen, E. F.: Stratospheric-Tropospheric Exchange bases based upon radioactivity, ozone and Potential Vorticity, J. Atmos. Sci., 25, 502-518, 1968.

Eisele, H., Scheel, H. E., Sladkovic, R., and Trickl, T.: High Resolution lidar measurements of stratosphere-troposphere exchange, J. Atmos. Sci., 56, 319-330, 1999.

Forster, C. and Wirth, V.: Radiative decay of an idealized stratospheric filaments in the tropoposphere, J. Geophys. Res., 105, $10169-10184,2000$.

Gray, L. J., Bithell, M., and Cox, B. D.: The role of specific humidity fields in the diagnosis of stratosphere troposphere exchange, Geophys. Res. Lett., 21, 2103-2106, 1994.

Hoinka, K. P., Richard, E., Poberaj, G., Busen, R., Caccia, J.-L., Fix, A., and Mannstein, H.: Analysis of a potential vorticity streamer crossing the Alps during MAP IOP-15 on 6 November
1999, Q. J. R. Meteorol. Soc., 129, 609-632, 2003.

Holton, J., Haynes, P. H., McIntyre, M. E., Douglass, A. R., Rood, R. B., and Pfister, L.: Stratosphere-Troposphere Exchange, Rev. Geophys., 33, 403-439 1995.

Knudsen, B. M. and Carver, G. D.: Accuracy of the isentropic trajectories calculated for the EASOE campaign, Geophys. Res. Lett., 21, 1199-1202, 1994.

Langford, A. O. and Reid, S. J.: Dissipation and mixing of a smallscale stratospheric intrusion in the upper troposphere, J. Geophys. Res., 103, 31 265-31 276, 1998.

Liniger, M. and Davies, H. C.: Sub-Structure of a MAP streamer, Q. J. R. Meteorol. Soc., 129, 633-651, 2003.

Massacand, A. C., Wernli, H., and Davies, H. C.: Heavy precipitation on the Alpine South side: An upper-level precursor, Geophys. Res. Lett., 25, 1435-1438, 1998.

Methven, J., Arnold, S. R., O’Connor, F. M., Barjat, H., Dewey, K., Kent, J., and Brough, N.: Estimating photochemically produced ozone throughout a domain using flight data and a Lagrangian model, J. Geophys. Res., 108(D9), 4271, doi:10.1029/2002JD002955, 2003.

Newell, R. E., Thouret, V., Cho, J. Y. N., Stoller, P., Marenco, A., and Smit, H. G.: Ubiquity of quasi horizontal layers in the troposphere, Nature, 398, 316-319, 1999.

Orsolini, Y. J., Manney, G. L, Engel, A., Ovarlez, J., Claud, C., and Coy, L.: Layering in stratospheric profiles of long-lived trace species: Ballon-borne observations and modeling, J. Geophys. Res., 103, 5815-5825, 1998.

Pierrehumbert, R. T.: Lateral Mixing ratio as a source of subtropical tropospheric water vapor, Geophys. Res. Lett., 25, 151-154, 1998.

Ravetta, F. and Ancellet, G.: Identification of dynamical processes at the tropopause during the decay of a cut-off low using high resolution airborne lidar measurements, Mon. Wea. Rev., 128, 3252-3267, 2000.

Rossa, A. M., Wernli, H., and Davies, H. C.: Growth and Decay of an Extra Tropical Ciclone's PV Tower, Meteorol. Atmos. Phys., 73, 139-156, 2000.

Shapiro, M. A.: Turbulent mixing within tropopause folds as mechanism for the exchange of chemical constituents between the stratosphere and troposphere, J. Atmos. Sci., 37, 994-1004, 1980.

SPARC: Assessment of Upper Tropospheric and Stratospheric Water Vapour, edited by: Kley, D., Russell III, J. M., and Phillips, C., WMO/TD-No. 1043, SPARC Report No. 2, 2000.

Stohl, A.: Computation, accuracy and application of trajectories-a review and bibliography, Atmos. Environ., 32, 947-966,1998.

Stohl, A., Bonasoni, P., Cristofanelli, P., Collins, W., Feichter, J., Frank, A., Forster, C., Gerasopoulos, E., Gaggeler, H., James, P., Kentarchos, T., Kreipl, S., Kromp-Kolb, H., Kruger, B., Land, C., Meloen, J., Papayannis, A., Priller, A., Seibert, P., Sprenger, M., Roelofs, G. J., Scheel, E., Schnabel, C., Siegmund, P., Tobler, L., Trickl, T., Wernli, H., Wirth, V., Zanis, P., and Zerefos, C.: Stratosphere-troposphere exchange - a review, and what we have learned from STACCATO, J. Geophys. Res., 108(D12), 8516, doi:10.1029/2002JD002490, 2003.

Sutton, R. T., Maclean, H., Swinbank, R., O’Neill, A., and Taylor, F. W.: High resolution stratospheric tracer fields estimated from satellite observations using Lagrangian trajectory calculations, J. Atmos. Sci., 51, 2995-3005,1994. 
Vaughan, G., Price, J. D., and Howells, A.: Transport into the troposphere in a tropopause fold, Q. J. R. Meteorol. Soc., 120, 10851103, 1994.

Vaughan, G. and Worthington, R. M.: Break-up of a stratospheric streamer observed by MST radar, Q. J. R. Meteorol. Soc., 126, 1751-1769, 2000.
Wernli, H. and Davies, H. C.: A lagrangian based analysis of extra tropical cyclones I: The method and some applications, Q. J. R. Meteorol. Soc., 123, 467-489, 1997.

Whiteman, D. N., Melfi, S. H., and Ferrare, R. A.: Raman lidar system for the measurement of water vapor and aerosols in the Earth's atmosphere, Appl. Opt., 31, 3068-3081, 1992. 